\title{
Effect of vegetation on soil bacteria and their potential functions for ecological restoration in the Hulun Buir Sandy Land, China
}

\author{
YAN Ru${ }^{1}$, FENG Wei ${ }^{1,2^{*}}$ \\ ${ }^{1}$ Yanchi Research Station, School of Soil and Water Conservation, Beijing Forestry University, Beijing 100083, China; \\ ${ }^{2}$ Engineering Research Center of Forestry Ecological Engineering of the Ministry of Education, Beijing Forestry University, \\ Beijing 100083, China
}

\begin{abstract}
To date, much of research on revegetation has focused on soil microorganisms due to their contributions in the formation of soil and soil remediation process. However, little is known about the soil bacteria and their functions respond to the diverse vegetational types in the process of vegetation restoration. Effects of dominated vegetation, i.e., Artemisia halodendron Turcz Ex Bess, Caragana microphylla Lam., Hedysarum fruticosum Pall. and Pinus sylvestris L. on bacterial community structures and their potential functions in the Hulun Buir Sandy Land, China were determined using high-throughput 16S rRNA gene sequencing and phylogenetic investigation of communities by reconstruction of unobserved states (PICRUSt) in 2015. Although the dominant phyla of soil bacterial community among different types of vegetation, including Proteobacteria, Actinobacteria, Acidobacteria, Bacteroidetes and Firmicutes, were similar, the relative abundance of these dominant groups significantly differed, indicating that different types of vegetation might result in variations in the composition of soil bacterial community. In addition, functional genes of bacterial populations were similar among different types of vegetation, whereas its relative abundance was significantly differed. Most carbon fixation genes showed a high relative abundance in P. sylvestris, vs. recalcitrant carbon decomposition genes in $A$. balodendron, suggesting the variations in carbon cycling potential of different types of vegetation. Abundance of assimilatory nitrate reduction genes was the highest in P. sylvestris, vs. dissimilatory nitrate reduction and nitrate reductase genes in $A$. halodendron, indicating higher nitrogen gasification loss and lower nitrogen utilization gene functions in $A$. balodendron. The structures and functional genes of soil bacterial community showed marked sensitivities to different plant species, presenting the potentials for regulating soil carbon and nitrogen cycling.
\end{abstract}

Keywords: bacterial taxonomic composition; functional gene; vegetational type; soil carbon and nitrogen; 16S rRNA

Citation: YAN Ru, FENG Wei. 2020. Effect of vegetation on soil bacteria and their potential functions for ecological restoration in the Hulun Buir Sandy Land, China. Journal of Arid Land, 12(3): 473-494. https://doi.org/10.1007/s40333-020-0011-z

\section{Introduction}

Revegetation is considered as one of the most effective methods for constantly restoring degraded ecosystems and improving harsh environments (Liao et al., 2019), and prevails as an important tool in reversing desertification in northern China (Wang et al., 2013; Miyasaka et al., 2014). The application of vegetation restoration effectively prevents wind erosion ( $\mathrm{Li}$ et al., 2007; Pei et al.,

\footnotetext{
*Corresponding author: FENG Wei (E-mail: weifeng@bjfu.edu.cn)

Received 2019-09-06; revised 2020-02-27; accepted 2020-04-03

(C) Xinjiang Institute of Ecology and Geography, Chinese Academy of Sciences, Science Press and Springer-Verlag GmbH Germany, part of Springer Nature 2020
} 
2008), improves soil fertility, alters soil physical and chemical properties and even promotes soil formation (Yuan et al., 2012; Li et al., 2017; Sun et al., 2019). However, the interrelations between revegetation and soil microbial environments have not been sufficiently examined until very recently, and a substantial gap remains regarding how the soil biotic community responds to revegetation practices and how these changes influence soil functions, such as carbon and nitrogen fixation (Cheng et al., 2017; Deng et al., 2019).

Soil microbial communities are composed of multiple microbial populations, the structure of which is sensitive to micro-environments and affected by vegetational type and aboveground diversity (Ferran et al., 2013; Shihan et al., 2016). In particular, vegetation patches in desertification areas with a patchy landscape pattern can act as fertiliser islands that provide the nutrients and water for the recruitment of soil microbes (Goberna et al., 2007; Özçelik et al., 2019). A few previous studies have documented the revegetation effects on soil microbial community structure, and the majority addressed the effects of aboveground community characteristics (e.g., diversity, abundance and species composition) (Hacker et al., 2015; Prober et al., 2015), or focused on a single land use type (e.g., grassland, bush and forest) and a single revegetation species (Zhang et al., 2019). However, comparison among different types of vegetation is lacking. In particular, the variations in plant species give rise to environmental heterogeneity through different quantity and quality of litter, vegetation excretion and water availability, which offer sufficient conditions to alter the distribution patterns of soil microbial communities (Boeddinghaus et al., 2019; Zhang et al., 2019). Hence, it is important to gain a better understanding of the microbial distribution patterns under vegetation dominated by different plant species, which may in turn provide a novel approach to evaluate revegetation practices with respect to microbial community structure and composition, thus potentially offering suggestions regarding the selection of plant species for ecological restoration.

Vegetation cannot only affect the composition and distribution of soil microbial communities but also impact potential functions (Maestre et al., 2012; Zhou et al., 2019). Vegetation restoration affects soil carbon and nitrogen cycling by shifting the input and decomposition of soil organic matter (Liu et al., 2013; Chen et al., 2015) as well as other biological and non-biological processes (Li et al., 2012; Yang et al., 2014). Decomposition of plant residues both increases the soil organic carbon content and further releases carbon dioxide by metabolism and respiration (Schneider et al., 2012; Voriskova et al., 2013; Castro et al., 2019). Therefore, the analysis of the potential functions of soil bateria under different plant species can enhance our knowledge regarding the functions of microbial decomposition, nutrient transformation and plant growth promotion. This may in turn provide evidence for evaluating the contribution of sand stabilisation by revegetation to carbon and nitrogen cycling in desert ecosystems.

The Hulun Buir Sandy Land is located in a transitional zone from forest steppe to dry steppe in northeastern China (Zhang et al., 2013a). In recent decades, the land has undergone severe desertification resulting from long-term natural and anthropogenic disturbances, such as overgrazing, excessive farming and fuel wood gathering (Guo et al., 2010). Establishing the shrubs including Artemisia halodendron Turcz Ex Bess, Caragana microphylla Lam., Hedysarum fruticosum Pall. and Pinus sylvestris L. has constituted the main measures used for many years to abate wind-induced soil erosion and improve the environment in this region ( $\mathrm{Du}$ et al., 2012). Previous studies have shown the effects of revegetation on soil abiotic environment (e.g., microclimate, wind erosion and soil characteristics) (Wang et al., 2013; Fu et al., 2015); however, soil bacteria and their potential functions are poorly understood. To address this issue, we selected four types of dominated vegetation in the Hulun Buir Sandy Land to gain insight into the structure of soil bacterial community and predict their functional gene using high-throughput sequencing analysis methods and phylogenetic investigation of communities by reconstruction of unobserved states (PICRUSt; Langille et al., 2013; Xiao et al., 2017). Our study focused on two aims: (1) identifying the soil bacterial assemblages under different types of vegetation; and (2) determining how the soil bacteria affect soil carbon and nitrogen cycling under different types of vegetation. 


\section{Materials and methods}

\subsection{Study area, soil sampling and analysis}

The experiment was conducted at the Hulun Buir Sandy Land $\left(48^{\circ} 50.4^{\prime} \mathrm{N}, 119^{\circ} 54.0^{\prime} \mathrm{E} ; 670 \mathrm{~m}\right.$ a.s.1.), Ewenki Autonomous Banner, Inner Mongolia Autonomous Region in northeastern China. This area has a temperate semi-arid continental climate with $-2.6^{\circ} \mathrm{C}$ annual mean temperature and $307.7 \mathrm{~mm}$ mean annual precipitation received mainly in the summer and autumn (approximately $70 \%$ from June to September). The soil is classified as sandy chestnut and is susceptible to wind erosion (Zhang et al., 2013a). To control desertification, people have established the sand-fixation vegetation in this region since 2006. Before revegetation, the landscape was characterised as semi-fixed (with a vegetation coverage $<15 \%$ ) sandy lands, with the sparse xeric vegetation. Our study selected four types of vegetation that was dominated by P. sylvestris, C. microphylla, $H$. fruticosum and $A$. halodendron and these plant species had a similar restoration age (around 8 -year) and more than $60 \%$ vegetation coverage.

Field sampling was carried out in July 2015, near the period of the highest plant biomass production and species richness. A total of 12 plots of $20 \mathrm{~m} \times 20 \mathrm{~m}$ were established for the four types of vegetation, with each type of vegetation containing different plant species and having three replicates. Basic information of the sampled vegetation is shown in Table 1. In each plot, three plant species were randomly selected for soil sample collection and mixture. For each plant, we set two different patch types (beneath plant mid-canopy and plant interspace) to collect and mix four samples (north, south, east and west of the site) as one sample for each patch type. Soil samples $(0-10 \mathrm{~cm})$ were collected with a $4.5-\mathrm{cm}$ diameter soil auger, excluding the litter layer. Then, three samples in the same patch type were mixed to create one composite sample. A total of 24 composite samples were collected (four plant species $\times$ three replicates $\times$ two patch types). The composite soil samples were sieved through a $2.0-\mathrm{mm}$ mesh to remove roots and rocks, homogenised and separated into two parts, one being preserved for soil property analysis and the other being placed into a sterile plastic bag and immediately returned to the laboratory following storage in a vehicle refrigerator at $-18^{\circ} \mathrm{C}$. In the laboratory, samples were stored in a refrigerator at $-20^{\circ} \mathrm{C}$ to inhibit microbial metabolism before DNA extraction. It takes about 2-3 d from sample storage to DNA extraction (Sun et al., 2017).

Soil water content (SWC) was determined using the oven-drying method. Total soil organic carbon (SOC) was determined using the dichromate oxidation method (Walkley et al., 1934). Total nitrogen (TN) content was determined using a Kjeldahl Apparatus Nitrogen Analyser (FOSS2200, Foss, Denmark). Soil hydrolysable nitrogen (HN) was determined using the alkaline hydrolysis diffusion method. Total phosphorus (TP) and available phosphorus (AP) contents were measured using an ultraviolet spectrophotometer (Shimadzu UV- 2550, Kyoto, Japan). Soil pH was measured after creating a 1:2.5 $(25 \mathrm{~g} / 100 \mathrm{~mL})$ soil-to-distilled water slurry.

Table 1 Basic information of the sampled vegetation

\begin{tabular}{|c|c|c|c|c|}
\hline Dominant plant species & Vegetation coverage $(\%)$ & Mean height (m) & $\begin{array}{l}\text { Mean canopy } \\
\text { area }\left(\mathrm{m}^{2}\right)\end{array}$ & Main associated plant species \\
\hline Artemisia halodendron & 60 & 0.63 & 0.80 & $\begin{array}{c}\text { Cleistogenes; Saussurea salsa; } \\
\text { Agropyron cristatum }\end{array}$ \\
\hline Caragana microphylla & 85 & 1.30 & 4.41 & $\begin{array}{c}\text { Setaria viridis; Agropyron } \\
\text { cristatum; Cleistogenes squarrosa }\end{array}$ \\
\hline Hedysarum fruticosum & 90 & 1.40 & 6.19 & $\begin{array}{l}\text { Cleistogenes squarrosa; Setaria } \\
\text { viridis; Agropyron cristatum }\end{array}$ \\
\hline Pinus sylvestris & 70 & 5.00 & 7.84 & $\begin{array}{c}\text { Saussurea salsa; Artemisia } \\
\text { frigida; Carex spp. }\end{array}$ \\
\hline
\end{tabular}

\subsection{Microbial sequencing analysis}

DNA was extracted from the $0.2 \mathrm{~g}$ homogenised soil sample using the E.Z.N.A. ${ }^{\circledR}$ soil DNA kit (D5625-01; Omega Bio-tek, Norcross, GA, USA) following the manufacturer's instructions. The V3 and V4 regions of the 16S rRNA gene amplicon for bacteria were sequenced by the Sangon Biotech Co. Ltd. (Shanghai, China), where they were defrosted and analysed using the Illumina 
MiSeq sequencing system (Illumina, San Diego, CA, USA) with the $341 \mathrm{~F}$ (5'-CCCTACACGACGCTCTTCCGATCTG (barcode) CCTACGG-GNGGCWGCAG-3') and 805R (5'-GACTGGAGTTCCTTGGCACCCGAGAATT-CCAGACTACHVGGGTATCTAATCC $\left.-3^{\prime}\right)$ primers set. The sequences were clustered into operational taxonomic units (OTUs) at the $\geq 97 \%$ identity threshold using Uclust v1.1.579 (Edgar, 2010), after being merged (Magoč et al., 2011) and filtered (Edgar et al., 2011). Taxonomic assignment was performed using the Ribosomal Database Project (RDP) classifier. The relative abundance of different phyla or other taxonomic categories in each sample was calculated. Alpha diversity index was calculated using Mothur v1.30.1 (Kozich et al., 2013). Full details of the DNA extraction, sequencing and bioinformatics processing followed the method described by Sun et al. (2017).

We used PICRUSt to investigate the metabolic potential of the soil bacteria. The OTU table was input into PICRUSt on the Galaxy web platform (Goecks et al., 2010) for metagenome prediction using the Kyoto Encyclopedia of Genes and Genomes (KEGG) database. The output results consisted of tables of predicted functional gene (KEGG Ortholog) abundance at various levels.

\subsection{Statistical analyses}

Two-way ANOVAs (analysis of variances) were performed to test the effects of vegetation, patch type and their interaction on soil properties, soil bacterial diversity, relative abundance of soil bacteria and relative abundance of functional genes. The differences of these variables were compared among four types of vegetation using one-way ANOVA for normal distribution or the Kruskal-Wallis test for non-normal distribution. Post-hoc comparisons were performed using Tukey's Honestly Significant Difference Test or Wilcoxon test. Bartlett and Shapiro-Wilk tests were used to check the homogeneity of variance and normality, respectively. All statistical analyses were performed using SAS JMP Statistical Discovery v11.0 (Cary, NC, USA). Further statistical analyses were performed using R software v3.3.2 (R Development Core Team, R Foundation for Statistical Computing, Vienna, Austria). Alpha diversity was calculated using the Shannon index and Chao1, and beta diversity was shown by non-metric multidimensional scaling (NMDS) with the Bray-Curtis index (Sun et al., 2017). The redundancy analysis (RDA) and Mantel test were used to determine the major environmental attributes shaping bacterial structures. RDA was determined by the variance inflation factors (VIF) with attributes having VIF over 20 removed and detrended correspondence analysis (DCA) with the maximum axis lengths less than 3. A heat map was used to analyse the differences in relative abundance of functional genes of four types of vegetation.

\section{Results}

\subsection{Soil property and soil bacterial diversity}

Soil property and soil bacterial diversity are shown in Table 2 . The contents of SOC, TN, HN, pH, Shannon index and Chaol were significantly different among four types of vegetation $(P<0.05)$. The contents of SOC and TN were also influenced by patch types with SOC content being markedly higher in the soil beneath plant mid-canopy than plant interspace in $H$. fruticosum $(P<0.05)$. The interaction between vegetation and patch type had non-significant effect on soil property. Moreover, values of SOC, TN, HN, Shannon index and Chaol were markedly higher in $P$. sylvestris and lower in $A$. halodendron than in the other plant species $(P<0.05)$, whereas $\mathrm{pH}$ value showed a reverse trend $(P<0.05)$. Conversely, values of TP, AP, SWC and EC did not exhibit significant differences among four types of vegetation $(P<0.05)$.

\subsection{Diversity of bacterial community}

Across all samples, a total of 431,792 high-quality microbial sequences were identified before resampling with an average of 17,991 sequences per sample (ranging from 10,828 to 32,697). The sequences were grouped into 72,679 OTUs using an arbitrary $97 \%$ sequence similarity cut-off. These sequences were classified into 49 phyla, 86 classes, 117 orders, 279 families and 1217 genera. 
Table 2 ANOVA results of soil property and bacterial diversity under different types of vegetation and patch types

\begin{tabular}{|c|c|c|c|c|c|c|c|c|c|c|}
\hline \multirow{3}{*}{ Variable } & \multicolumn{6}{|c|}{ Two way ANOVAs } & \multicolumn{4}{|c|}{ One way ANOVA } \\
\hline & \multicolumn{2}{|c|}{ Vegetation } & \multicolumn{2}{|c|}{ Patch type } & \multicolumn{2}{|c|}{ Vegetation $\times$ Patch type } & \multirow{2}{*}{$\mathrm{AH}$} & \multirow{2}{*}{$\mathrm{CM}$} & \multirow{2}{*}{$\mathrm{HF}$} & \multirow{2}{*}{ PS } \\
\hline & $F$ & $P$ & $F$ & $P$ & $F$ & $P$ & & & & \\
\hline \multicolumn{11}{|l|}{ Soil property } \\
\hline SOC & 7.00 & 0.003 & 15.05 & 0.001 & 2.25 & 0.122 & $1.47^{\mathrm{b}}$ & $1.32^{\mathrm{b}}$ & $1.97^{\mathrm{ab}}$ & $2.37^{\mathrm{a}}$ \\
\hline $\mathrm{TN}$ & 6.37 & 0.005 & 7.04 & 0.017 & 1.66 & 0.216 & $0.06^{\mathrm{b}}$ & $0.13^{\mathrm{a}}$ & $0.13^{\mathrm{a}}$ & $0.13^{\mathrm{a}}$ \\
\hline $\mathrm{HN}$ & 9.63 & 0.001 & 2.38 & 0.142 & 1.50 & 0.252 & $7.93^{\mathrm{b}}$ & $13.91^{\mathrm{a}}$ & $15.59^{\mathrm{a}}$ & $14.86^{\mathrm{a}}$ \\
\hline TP & 1.99 & 0.157 & 0.03 & 0.866 & 0.94 & 0.446 & 91.60 & 81.64 & 86.86 & 67.72 \\
\hline $\mathrm{AP}$ & 2.46 & 0.100 & 1.99 & 0.178 & 0.10 & 0.961 & 4.22 & 4.68 & 4.88 & 6.02 \\
\hline SWC & 1.96 & 0.161 & 0.02 & 0.881 & 0.69 & 0.571 & 0.03 & 0.02 & 0.03 & 0.01 \\
\hline $\mathrm{EC}$ & 1.81 & 0.187 & 3.65 & 0.074 & 0.81 & 0.508 & 29.22 & 31.59 & 23.50 & 24.44 \\
\hline $\mathrm{pH}$ & 7.25 & 0.003 & 0.25 & 0.625 & 1.86 & 0.177 & $7.20^{\mathrm{a}}$ & $6.86^{\mathrm{ab}}$ & $6.66^{\mathrm{b}}$ & $6.71^{\mathrm{b}}$ \\
\hline \multicolumn{11}{|c|}{ Soil bacterial diversity } \\
\hline Shannon & 9.07 & 0.001 & 4.21 & 0.057 & 0.84 & 0.491 & $7.68^{b}$ & $7.91^{\mathrm{b}}$ & $7.88^{\mathrm{b}}$ & $8.24^{\mathrm{a}}$ \\
\hline Chaol & 5.78 & 0.007 & 1.49 & 0.240 & 0.69 & 0.570 & $14,042.00^{\mathrm{b}}$ & $18,893.00^{\mathrm{ab}}$ & $17,517.00^{\mathrm{ab}}$ & $21,574.00^{\mathrm{a}}$ \\
\hline
\end{tabular}

Note: $F$ value is the ratio of mean variance between groups to mean variance within groups. $P$ value is statistical significance. AH, Artemisia halodendron; CM, Caragana microphylla; HF, Hedysarum fruticosum; PS, Pinus sylvestris. SOC, soil organic carbon; TN, total nitrogen; HN, hydrolytic nitrogen; TP, total phosphorus; AP, available phosphorus; SWC, soil water content; EC, electrical conductivity. Different lowercase letters within the same row indicate significance among four types of vegetation at $P<0.05$ level.

Bacterial alpha diversity was estimated by OTU richness (Chao1) and Shannon index. The richness of the bacterial community ranged from 11,650 to 27,976 phylotypes per sample with all samples obtained from an identical sequencing depth. The average number of bacterial alpha diversity indices (Chaol and Shannon index) of each type of vegetation followed the order $A$. halodendron $<H$. fruticosum $<$ C. microphylla $<$ P. sylvestris (Table 2). Additionally, of all environmental variables examined, SOC, TN and $\mathrm{HN}$ were most correlated with Shannon index and Chao1. Moreover, TP, AP and SWC were also correlated with Shannon index $(P<0.05)$, whereas soil $\mathrm{pH}$ and EC were not correlated with soil bacterial alpha diversity (Table 3 ).

Table 3 Spearman correlation coefficient between soil bacterial alpha diversity (Shannon index and Chao1) and environmental variable

\begin{tabular}{ccccccccc}
\hline Index & SOC & TN & TP & AP & HN & SWC & pH & EC \\
\hline Shannon & $0.5365^{* *}$ & $0.5336^{* *}$ & $-0.5365^{* *}$ & $0.5044^{* *}$ & $0.5997^{* *}$ & $-0.4652^{*}$ & -0.3197 & 0.1587 \\
Chao1 & $0.4374^{*}$ & $0.5653^{* *}$ & -0.3530 & 0.4043 & $0.4410^{*}$ & -0.3652 & -0.3071 & 0.0752 \\
\hline
\end{tabular}

Note: SOC, soil organic carbon; TN, total nitrogen; TP, total phosphorus; AP, available phosphorus; HN, hydrolytic nitrogen; SWC, soil water content; EC, electrical conductivity; ${ }^{*}$ and ${ }^{* *}$ represent significant correlations at $P<0.05$ and $P<0.01$ levels, respectively.

The NMDS plot of Bray-Curtis distance ordination clearly showed that points of the same vegetation were clustered together (Fig. 1). Significant differences were observed in the soil bacterial community composition $(P<0.05)$ among four types of vegetation pairings by ANOSIM (analysis of similarities) analysis (Table 4), with the exception of $C$. microphylla and $H$. fruticosum.

\subsection{Taxonomic composition of soil bacterial community}

As shown in Figure 2, the phyla including Proteobacteria, Actinobacteria, Acidobacteria, Bacteroidetes and Firmicutes accounted for more than $70 \%$ of the bacterial sequences in the four types of vegetation. Additional phyla including Chlamydia, Gemmatimonadetes, Nitrospirae, Planctomycetes, Verrucomicrobia and Candidatus Saccharibacteria (relative abundance $>1 \%$ ) were also found in all soil samples; however, the genera (relative abundance $>1 \%$ ) showed significant differences among four types of vegetation.

Further analysis of the relative abundance of dominant soil bacterial phyla and genera (Fig. 2 and Table S1) indicated that vegetation had a significant effect on the relative abundance of most 


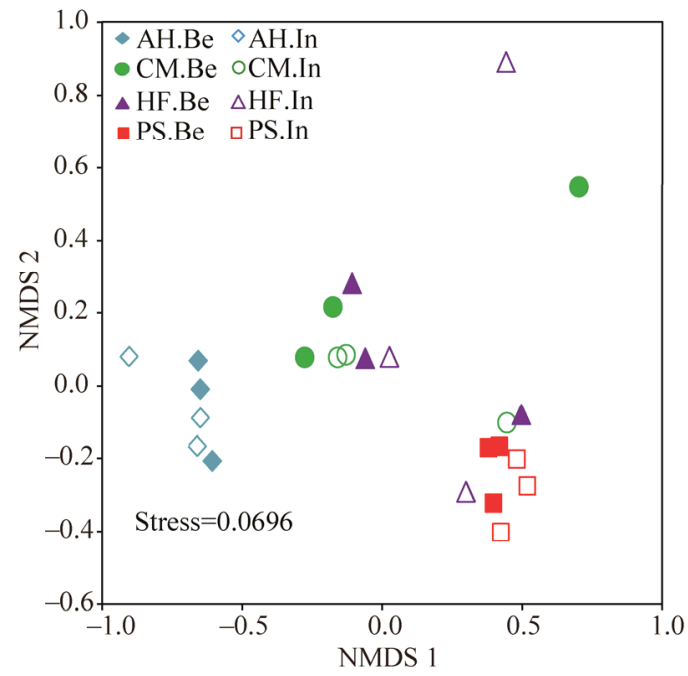

Fig. 1 Non-metric multidimensional scaling (NMDS) ordination based on Bray-Curtis distance showing soil bacterial beta diversity under different vegetation and patch types. AH, Artemisia halodendron; CM, Caragana microphylla; HF, Hedysarum fruticosum; PS, Pinus sylvestris; Be, beneath plant mid-canopy; In, plant interspace.

Table 4 Significance test on the effects of different types of vegetation pairings on the soil bacterial community structure as detected by the analysis of similarities (ANOSIM)

\begin{tabular}{ccc}
\hline Vegetation pairing & $r$ & $P$ \\
\hline AH-CM & 0.5741 & 0.003 \\
AH-HF & 0.7185 & 0.001 \\
AH-PS & 1.0000 & 0.002 \\
CM-HF & -0.0852 & 0.752 \\
CM-PS & 0.4953 & 0.006 \\
HF-PS & 0.3722 & 0.005 \\
\hline
\end{tabular}

Note: AH, Artemisia halodendron; CM, Caragana microphylla; HF, Hedysarum fruticosum; PS, Pinus sylvestris. $r$, correlation coefficient; $P$, statistical significance.

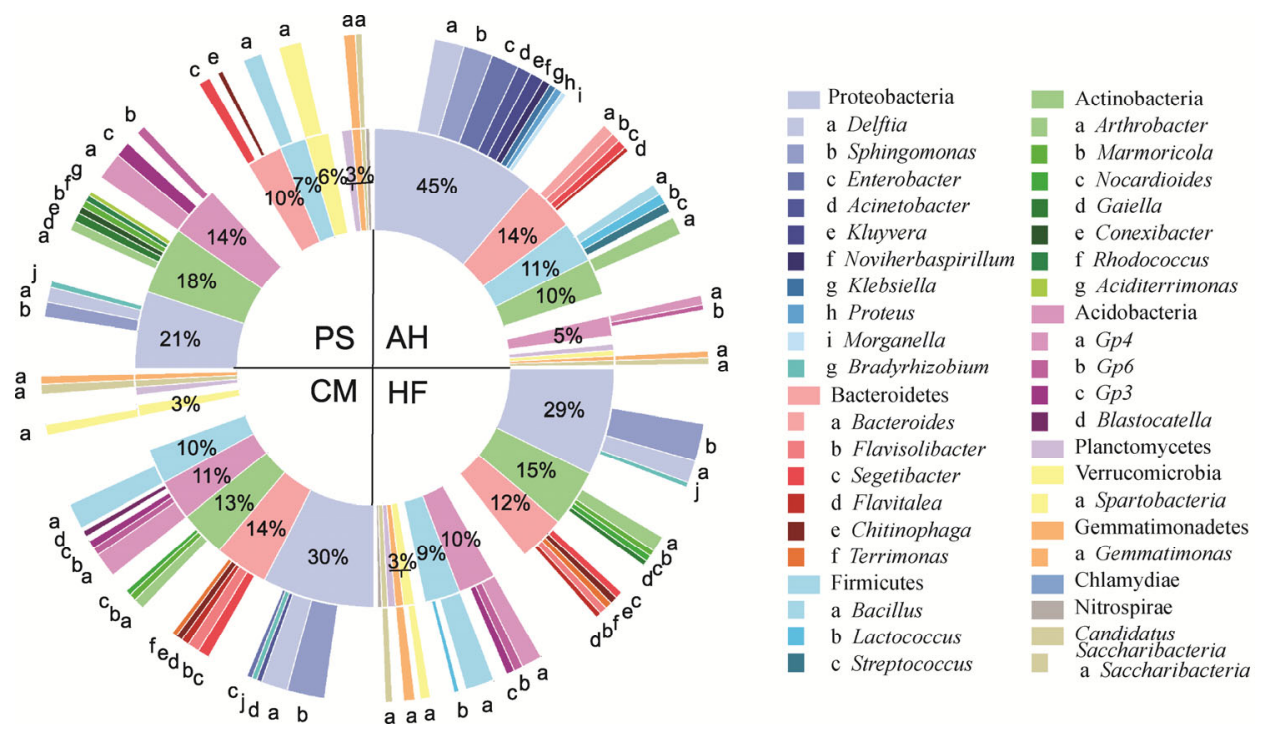

Fig. 2 Bacteria taxonomic classification at the phyla and genus levels. The inner circle is the dominant phyla (relative abundance $>1 \%$ ), and the outer circle is the dominant genus (relative abundance $>1 \%$ ). The same colour represents a phylum, and the lowercase letters in each colour represent a certain genus in the phylum. Each quarter represents a plant species. PS, Pinus sylvestris; AH, Artemisia halodendron; CM, Caragana microphylla; $\mathrm{HF}$, Hedysarum fruticosum. 
dominant phyla, except for Bacteroidetes, Firmicutes and Planctomycetes $(P<0.05)$. In particular, the relative abundance of Proteobacteria was significantly higher in A. halodendron than in the other plant species $(P<0.05)$. The relative abundance of Acidobacteria, Actinobacteria, Chlamydia, Nitrospirae and Verrucomicrobia was higher in P. sylvestris than in the other plant species. No significant effects of patch type were found in the relative abundance of all bacterial phyla.

The relative abundance of most genera in the Proteobacteria division was higher in $A$. halodendron, except for Sphingomonas, Bradyrhizobium, Rhizobium, Mesorhizobium and Microvirga spp. The relative abundance of Bradyrhizobium, Rhizobium and Mesorhizobium that are symbiotic nitrogen fixation bacteria, was higher in $C$. microphylla and $H$. fruticosum than in the other two plant species. Additionally, Bactericides (Bacteroidetes), Lactococcus and Streptococcus (Firmicutes) were significantly higher in A. halodendron than in the other plant species $(P<0.05)$. The relative abundance of Nocardioides, Blastocatella, Flavitalea, Terrimonas, Bacillus and Nitrospira were significantly higher in C. microphylla and H. fruticosum than in the other two plant species $(P<0.05)$. Except for these, the other genera that were affected by vegetation were significantly higher in $P$. sylvestris than in the other plant species $(P<0.05)$. Only genera Terrimonas and Ferruginibacter were affected by patch type, exhibiting a higher relative abundance beneath plant mid-canopy.

\subsection{Structure of potential functional gene of soil bacteria}

The heat map (Fig. 3) showed that the abundance of most carbon fixation genes and methanogenesis genes under different types of vegetation followed the order of $P$. sylvestris $>H$. fruticosum $>C$. microphylla $>A$. halodendron, except that genes $p c k A$ and $p p c$ showed the highest abundance in $A$. halodendron. The dominant genes (relative abundance $>0.025 \%$ ) of carbon fixation found in all soil samplings were $I D H 1, \operatorname{coxS}$, coxM, pckA, korA, korB and pcc. For carbon degradation genes (Fig. 3), a multitude of cellulose degradation and hemi-cellulose degradation genes appeared to govern carbon degradation processes as they were detected in a high abundance across all samples, and included man, $x y n A$, abf $A$, beta-glucosidase, bglx, bglB, bglA and endoglucanase. The genes amy $A$ and chitinase were also detected in a large proportion. Among carbon degradation genes, amy $A, p u l A, b g l B, c e l F, b g l A$, putative chitinase, chitinase and pectinesterase were significantly higher in $A$. halodendron $(P<0.05)$. In contrast, the genes glucoamylase, man, $x y n A, a b f A, b g l X$, endoglucanase and polygalacturonase were significantly higher in $P$. sylvestris $(P<0.05)$. In addition, only a few genes $(c d$, man, $x y n A$ and endoglucanase $)$ were influenced by patch type in $P$. sylvestris.

Figure 3 also showed that the gene abundance of nitrogen fixation (nifH, nifD and nifK), nitrification (hao), and denitrification (nirK) was significantly lower in A. halodendron $(P<0.05)$, whereas the abundance of nitrogen reduction genes was higher than those in the other plant species. For nitrate reduction, the relative abundance of $\operatorname{nar} G, \operatorname{narH}, \operatorname{narI}, \operatorname{nap} A, \operatorname{nap} B$, nirB and $n a s A$ was significantly higher in $A$. halodendron $(P<0.05)$. Specifically, genes of narB and nirA, whose function occurred in dissimilatory nitrate reduction and assimilatory nitrate reduction, respectively, showed a higher abundance in $P$. sylvestris. In addition, the dominant genes of nitrogen metabolism were $\operatorname{nir} B, \operatorname{nir} D$ and nas $A$. The patch type had no effect on the relative abundance of nitrogen cycling genes (Fig. 3 and Table S2).

\subsection{Relationships of soil variable with bacterial community structure and functional gene}

The RDA was performed to identify the major soil variables influencing the formation of bacterial community structure. VIFs and BIO-ENV were used to eliminate multicollinearity among variables. We selected four variables as inputs for the RDA (Fig. 4). As shown in Figure 4a, bacterial diversity, SOC, TN, HN, TP and SWC showed significant relationships with bacterial community structure $(P<0.05)$, which was also supported by the Mantel test at $P<0.05$ level (Table 5). In addition, soil bacterial communities were clearly separated among four types of vegetation despite an occasional overlap. Furthermore, variance partition analysis was subsequently performed to dissect the contribution of vegetation and environmental variables to bacterial community structure (Fig. 4c). A total of $53.1 \%$ of the community variations could be explained by these selected variables. Vegetation and soil variables contributed to $19.7 \%$ and 

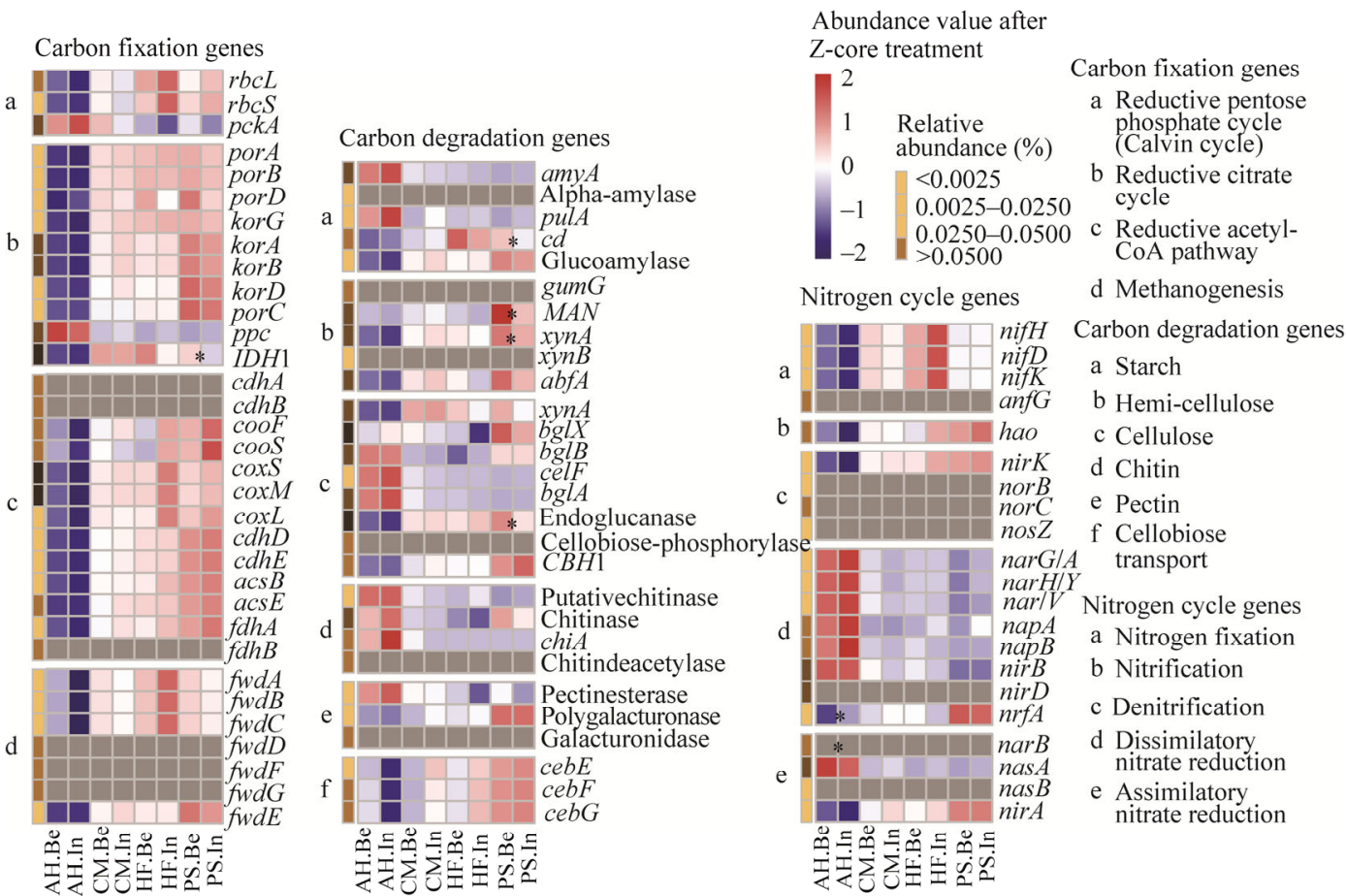

Fig. 3 Heat map indicating difference in the relative abundance of specific genes among four types of vegetation. AH, Artemisia halodendron; CM, Caragana microphylla; HF, Hedysarum fruticosum; PS, Pinus sylvestris; Be, beneath plant mid-canopy; In, plant interspace. * represents the significant difference between beneath plant mid-canopy and plant interspace at $P<0.05$ level.

Table 5 Correlations of environmental variable with bacterial community structure and functional gene

\begin{tabular}{|c|c|c|c|c|c|}
\hline \multirow{2}{*}{ Index } & \multicolumn{2}{|c|}{ Bacterial community structure } & \multirow{2}{*}{ Index } & \multicolumn{2}{|c|}{ Functional gene } \\
\hline & $r$ & $P$ & & $r$ & $P$ \\
\hline Bdiv & 0.3628 & 0.001 & Bdiv & 0.3624 & 0.001 \\
\hline TP & 0.3101 & 0.002 & TP & 0.2341 & 0.006 \\
\hline $\mathrm{HN}$ & 0.289 & 0.004 & $\mathrm{HN}$ & 0.3198 & 0.006 \\
\hline $\mathrm{TN}$ & 0.2581 & 0.006 & $\mathrm{TN}$ & 0.2587 & 0.006 \\
\hline SWC & 0.2065 & 0.009 & SWC & 0.2099 & 0.008 \\
\hline $\mathrm{SOC}$ & 0.1658 & 0.034 & $\mathrm{SOC}$ & 0.1041 & 0.081 \\
\hline AP & 0.1484 & 0.055 & AP & 0.0101 & 0.418 \\
\hline $\mathrm{pH}$ & 0.1298 & 0.096 & $\mathrm{pH}$ & 0.2179 & 0.014 \\
\hline $\mathrm{EC}$ & 0.0370 & 0.284 & $\mathrm{EC}$ & 0.0574 & 0.215 \\
\hline $\mathrm{Bdiv}+\mathrm{TP}$ & 0.4626 & 0.001 & $\mathrm{Bdiv}+\mathrm{HN}$ & 0.4235 & 0.001 \\
\hline $\mathrm{Bdiv}+\mathrm{TP}+\mathrm{HN}$ & 0.5024 & 0.001 & $\mathrm{Bdiv}+\mathrm{HN}+\mathrm{TN}$ & 0.4011 & 0.001 \\
\hline $\mathrm{Bdiv}+\mathrm{TP}+\mathrm{HN}+\mathrm{TN}$ & 0.4595 & 0.001 & $\mathrm{Bdiv}+\mathrm{HN}+\mathrm{TP}$ & 0.4396 & 0.001 \\
\hline $\mathrm{Bdiv}+\mathrm{TP}+\mathrm{HN}+\mathrm{SWC}$ & 0.4944 & 0.001 & $\mathrm{Bdiv}+\mathrm{HN}+\mathrm{TP}+\mathrm{pH}$ & 0.4744 & 0.001 \\
\hline $\mathrm{Bdiv}+\mathrm{TP}+\mathrm{HN}+\mathrm{SOC}$ & 0.4815 & 0.001 & $\mathrm{Bdiv}+\mathrm{HN}+\mathrm{TP}+\mathrm{pH}+\mathrm{SWC}$ & 0.4844 & 0.001 \\
\hline $\mathrm{Bdiv}+\mathrm{TP}+\mathrm{HN}+\mathrm{AP}$ & 0.5037 & 0.001 & $\mathrm{Bdiv}+\mathrm{HN}+\mathrm{TP}+\mathrm{pH}+\mathrm{SWC}+\mathrm{EC}$ & 0.4732 & 0.001 \\
\hline $\mathrm{Bdiv}+\mathrm{TP}+\mathrm{HN}+\mathrm{AP}+\mathrm{pH}$ & 0.4694 & 0.001 & $\mathrm{Bdiv}+\mathrm{HN}+\mathrm{TP}+\mathrm{pH}+\mathrm{SWC}+\mathrm{AP}$ & 0.4511 & 0.001 \\
\hline $\mathrm{Bdiv}+\mathrm{TP}+\mathrm{HN}+\mathrm{AP}+\mathrm{EC}$ & 0.4772 & 0.001 & & & \\
\hline
\end{tabular}

Note: Bdiv, bacterial diversity; TP, total phosphorus; HN, hydrolytic nitrogen; TN, total nitrogen; SWC, soil water content; SOC, soil organic carbon; AP, available phosphorus; EC, electrical conductivity. Correlation $(r)$ and significance $(P)$ were determined by the Mantel test based on 9999 permutations between community structure (Bray-Curtis distance) and environmental variables (Standardized Euclidean distance). 
$10.0 \%$ of the total variance, respectively, and together contributed $23.3 \%$ of the total variance.

We also used the same process to identify the major soil variables shaping functional genes. The top six variables including bacterial diversity, HN, TP, SWC, TN and $\mathrm{pH}$ that depended on VIF and BIO-ENV were selected. These variables showed significant relationships $(P<0.05)$ with functional genes, as supported by RDA (Fig. 4b) and the Mantel test (Table 5). Additionally, the samples from the same plant species were clustered together. A total of $78.5 \%$ of the bacterial community variation could be explained by these selected variables. Vegetation and soil variables contributed to $23.1 \%$ and $6.1 \%$ of the total variance, respectively, together contributing $49.3 \%$ of the total variance (Fig. 4 d).

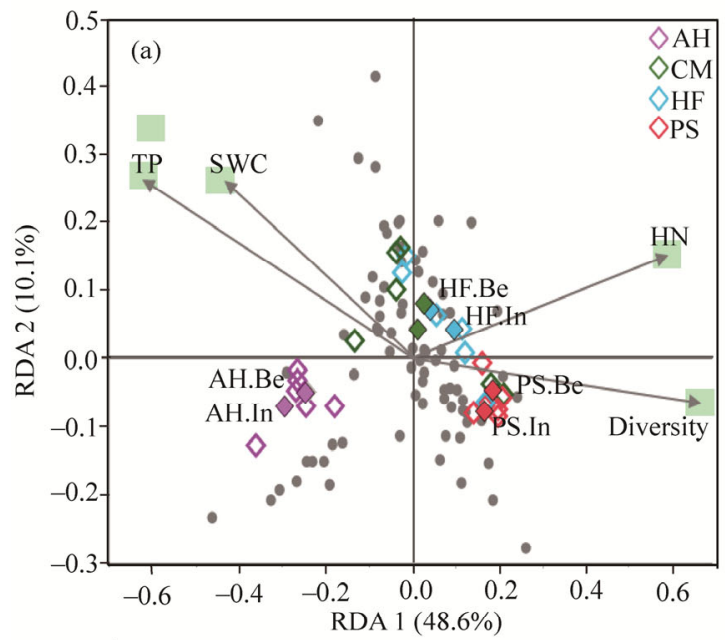

(c)
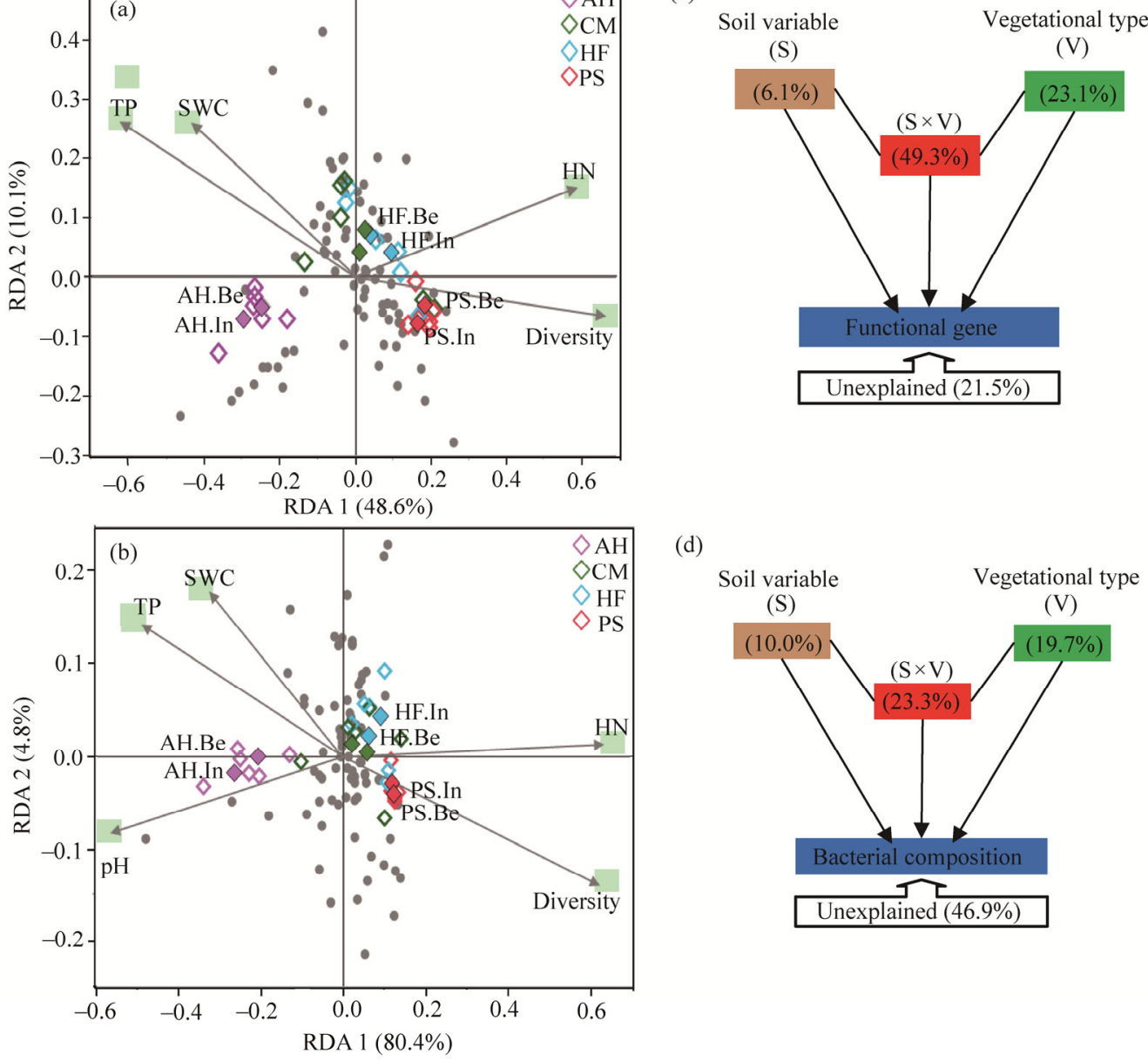

(d)

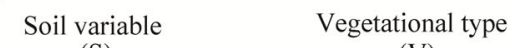

(S)

(V)

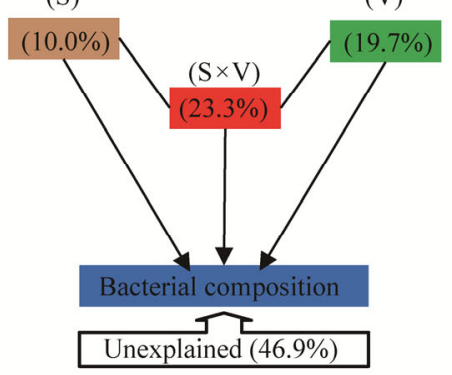

Fig. 4 Relationships of soil variable with bacterial community structure (a) and functional gene (b). Variation partitioning analyses of soil variable and vegetational type on functional gene (c) and bacterial composition (d). SOC, soil organic carbon; TN, total nitrogen; HN, hydrolytic nitrogen; TP, total phosphorus; AP, available phosphorus; SWC, soil water content; EC, electrical conductivity. AH, Artemisia halodendron; CM, Caragana microphylla; HF, Hedysarum fruticosum; PS, Pinus sylvestris. The environmental variables are divided into groups of soil (SOC, TN, TP, AP, HN, SWC, EC, $\mathrm{pH}$ and bacterial diversity) and vegetation. The numbers present percentage $(\%)$ of variation explained by the factors.

\section{Discussion}

\subsection{Difference of soil bacterial community structure under different types of vegetation}

As expected, all soil samples had the same dominant bacterial phyla of Proteobacteria, Actinobacteria, Acidobacteria, Bacteroidetes and Firmicutes (Fig. 2). These dominant phyla are 
ubiquitous in desert soils worldwide (Fierer et al., 2013). Among these bacterial phyla, Proteobacteria dominated all soil samples (Fig. 2) in our study, which agreed with previous surveys of the Tengger Desert, Horqin Sandy Land and Mu Us Sandy Land (Zhang et al., 2012; Jiang et al., 2013; She et al., 2018), but differed from Atacama Desert, Negev Desert and Taklimakan Desert where Actinobacteria dominated (Fierer et al., 2009; Orlando et al., 2010; Vered et al., 2011; Neilson et al., 2012; Wang et al., 2012; Yu et al., 2015). This could be due to Proteobacteria and Actinobacteria belong to the different ecological categories. Proteobacteria as the copiotrophic taxa preferentially consumed labile soil organic $\mathrm{C}$ pools with high nutritional requirements, and its relative abundance was positively correlated with soil carbon cycling and photosynthetic intensity of plants (Zeng et al., 2017; Che et al., 2019). In contrast, Actinobacteria as the oligotrophic taxa had a higher adaptive capacity under limited nutrients conditions (Fierer et al., 2007). In our study, soil samples were taken from vegetation restoration areas that had better soil conditions than the other barren deserts. Therefore, the relative abundance of Proteobacteria in this study was higher than that of Actinobacteria. Additionally, the weakly effect of different types of vegetation on soil bacterial populations could be due to the strong adaptability of dominant bacterial groups to environmental heterogeneity (Evans and Wallenstein, 2014). Many studies have shown that spatial patterns of soil microorganisms were shaped by environmental factors, such as soil pH (Griffiths et al., 2011; Feng et al., 2019), soil organic carbon (Chen et al., 2015; Zhao et al., 2016), climatic and geographic distance in a regional scale (Wang et al., 2015; Wang et al., 2017). However, without considering climatic and geographic distance in this study, we speculated that the environmental heterogeneity was primarily caused by different plant species. The variations of $\mathrm{pH}$ (6.66 to 7.2$)$, SOC (1.32 to $2.37 \mathrm{~g} / \mathrm{kg}$ ) and other soil chemistry were relatively smaller than that of ecological niche of bacteria, and therefore, they had a similar bacterial community.

Strikingly, the diversity indices (Chaol and Shannon) (Table 2) and the relative abundance of dominant phyla and genera (Figs. 1 and 2; Table 2) significantly varied with different types of vegetation, indicating that the application of different types of vegetation in degraded lands altered the bacterial diversity and bacterial community structure. One possible interpretation is that desert vegetation, compared with the other ecosystems, is discontinuous and patchy, and hence leading to a heterogeneous distribution of sediments, water and nutrients (Yadav et al., 2010; Chen et al., 2017; Unc et al., 2019). Under the inhomogeneous nutrition and water supply of different types of vegetation, soil microorganisms can adjust community structure to deal with the shortage of living resources. For example, our results showed that the positive correlation between soil fertility factors (SOC, TN and $\mathrm{HN}$ ) and soil bacterial diversity was found, and those indices were detected at significantly lower levels in A. halodendron than in P. sylvestris (Table 2). In addition, the relative abundance of Proteobacteria increased from $21 \%$ in $P$. sylvestris to $45 \%$ in A. halodendron (Fig. 2), while most other dominant phyla decreased in A. halodendron, e.g., Actinobacteria, Acidobacteria, Chlamydia, Nitrospirae and Verrucomicrobia. These results indicated that, in A. halodendron, soil bacterial community imposed limits on species diversity and evenness and consequently enhanced their capacity to adapt to soil nutrient deficiency. Thus, shifts in the vegetational type could affect soil bacteria community assembly by changing the bacterial living environment.

Also, desert vegetation provides an essential energy source for soil microbial communities through the production of litter and secretion of root exudates (Jangid et al., 2011; Zhang et al., $2013 \mathrm{~b}$ ), which may constitute another reason for the soil bacterial community structure variation after applied different types of vegetation. For instance, the number of dominant genera (relative abundance $>1 \%$ ) including Enterobacter, Klebsiella, Kluyvera and Morganella in the Proteobacteria division were enriched in A. halodendron. These genera comprise $\gamma$-proteobacteria and facultatively anaerobic bacteria that have a strong ability to adapt to the environment and may promote recalcitrant organic carbon decomposition and nitrogen fixation (Kim et al., 1998; Hayat et al., 2010). Compared with A. halodendron, we observed some genera were consistently enriched in the other vegetational types, e.g., Chitinophaga, Terrimonas, Gaiella, Conexibacter, Rhodococcus and Aciditerrimonas that have been shown to have the ability to promote recalcitrant organic carbon decomposition (Tiwari et al., 2013; Larsbrink et al., 2017). We also 
found that $C$. microphylla and $H$. fruticosum showed higher relative abundances of Bradyrhizobium, Rhizobium and Mesorhizobium, as they are legumes that form symbioses with nitrogen-fixing microorganism, thus resulting in the increased nitrogen input into the environment (Erisman et al., 2008; Gruber et al., 2008). Together these results suggested that aboveground vegetation could significantly affect the structure of soil microbial communities and select the soil microbes with which they associate.

To further evaluate the relative importance and effects of vegetational types and environmental parameters on the assembly of soil bacterial communities, we quantified their contributions through the redundancy analysis and variation partition analysis. We found that the interaction of vegetation and soil variable explained $23.3 \%$ of the variation in the assembly of bacterial communities, followed by vegetation (19.7\%) and soil variable (10.0\%) (Fig. 4c), indicating that both vegetational type and soil property had the ability to drive soil bacterial community structure and application of different types of vegetation led to a greater variation of bacterial assembly than soil variable. Furthermore, soil bacterial community structure analysis also indicated that the variations of bacterial community assembly were mainly attributed to the different types of vegetation (Fig. 4a). This further confirmed that vegetational types were significant in shaping the bacterial communities in the Hulun Buir Sandy Land and that plant species needed to be considered for ecological restoration. However, we also found that nearly half of the variation of bacterial community assembly was not explained, indicating that bacterial community was shaped not only by the vegetation and soil variable parameters but also by the other factors such as climate, $\mathrm{pH}$ and distance (Zhang et al., 2013; Cao et al., 2016).

\subsection{Difference of soil bacterial functional gene under different types of vegetation}

Microbes are crucial for ecosystem function as important engines in driving biogeochemical processes such as carbon and nitrogen cycling (Madsen, 2011; Schimel et al., 2012; Nelson et al., 2016). Although vegetation is various in assembly of soil bacterial community, it is difficult to evaluate its contribution in regulating material and energy flow of degeneration ecosystem via the composition of the dominant bacterial species. To address it, we adopted KEGG to evaluate the differences in functional potential of the soil bacterial community under different types of vegetation. Our research showed that the samples from four types of vegetation displayed similar KEGG profiles (Fig. 3), suggesting that vegetation did not influence the dominant genes of carbon and nitrogen cycling. However, the distinctly different plant species altered the relative abundance of dominant genes. These results showed that variations of functional genes were consistent with the changes in soil bacterial community, indicating that different types of vegetation constituted an important factor in driving the relative abundance of soil bacteria to regulate soil nutrient cycling. On the other hand, our results showed only $6.1 \%$ of the variations of the functional genes were attributed to the soil variable, while interaction of vegetation and soil variable explained $49.3 \%$ and vegetational type explained $23.1 \%$ (Fig. 4d), respectively. This further confirmed that vegetational type was significant in driving microbe-mediated carbon and nitrogen cycling in the Hulun Buir Sandy Land.

With respect to the carbon cycle, carbon fixation genes were dominated by $p c k A, p p c, k o r A$, $\operatorname{kor} B, I D H 1, \operatorname{cox} S$ and $\operatorname{cox} M$ (Fig. 3). This suggested that the main carbon-fixation processes were $\mathrm{C}_{4}$ Dicarboxylic Acid Cycle, Reductive Citrate Cycle and Reductive Acetyl-CoA pathway in the Hulun Buir Sandy Land. Interestingly, abundances of most carbon fixation genes were significantly higher in $P$. sylvestris, only the genes $p c k A$ and $p p c$ related to $\mathrm{C}_{4}$ Dicarboxylic Acid Cycle were higher in A. halodendron (Fig. 3), suggesting that the bacteria in P. sylvestris can facilitate the accumulation of carbon. Meanwhile, different dominant labile carbon degradation genes were detected in different types of vegetation, while most recalcitrant carbon degradation genes were higher in $A$. halodendron in terms of their relative abundances, indicating that microbe-mediated carbon decomposition was higher in $A$. halodendron. These results indicated that application of different types of vegetation led to a greater variation in carbon cycling genes and consequently affected soil carbon reservoir. This might be a reason for the higher and lower respective soil organic carbon contents in P. sylvestris and A. halodendron (Table 2).

For nitrogen cycling genes, higher abundant genes of nitrate reduction were detected than the 
other genes involved in the nitrogen cycle (Fig. 3). Nitrate reduction is a major source of nitrite for aerobic nitrite oxidation and anammox (Kuypers et al., 2018), which converts nitrite to nitric oxide and dinitrogen gas. Although we did not detect the key gene $h z s$ that catalysed the hydrazine production from ammonia and nitric oxide (Tu et al., 2017; Kuypers et al., 2018), we found abundant gene nirB encoding nitrite reductase (NADH) large subunit that supplied ammonia for anammox (Fig. 3). These results might implicate that denitrification and anammox processes were the major process of nitrogen emission of the Hulun Buir Sandy Land. Furthermore, our results showed that nar, nap and nas converting nitrate into nitrite were more abundant in $A$. halodendron, indicating that more nitrogen emission occurred in A. halodendron than in the other three plant species. In addition, $\operatorname{nir} B$ involved in dissimilatory nitrate reduction to ammonium was abundant in $A$. halodendron, whereas $n r f A$ involved in assimilatory nitrate reduction to ammonium was abundant in P. sylvestris (Fig. 3). This indicated that more ammonium of dissimilatory nitrate reduction could combine with the nitrite, thus resulting in the loss of nitrogen to the atmosphere in A. halodendron, and that more ammonium of assimilatory nitrate reduction as a nitrogen source was absorbed in $P$. sylvestris. This may underlie why the TN and $\mathrm{HN}$ contents were lower in A. halodendron (Table 2).

It should be noted that, although our results confirm that different types of vegetation alters soil bacterial community structure and potential functional gene, the effect of vegetation on the soil fungi structure and distribution remains unknown. Fungi, as important components of soil microorganisms, have a competitive advantage over many bacteria in decomposing tissues with low nutrient concentrations because of their ability to import nitrogen and phosphorus (Marcel et al., 2008; Chen et al., 2015; Zhao et al., 2019). Therefore, the study of plant-related fungi will help to further understand the community structure and functional gene of bacterial during the process of ecosystem rehabilitation in drylands.

\section{Conclusions}

This study revealed the responses of soil bacteria and their potential functions to different plant-dominated revegetation of the Hulun Buir Sandy Land, which may be of significance in evaluating the optimal plant species for ecological restoration in the desert ecosystems. The dominant soil bacterial phyla under different types of vegetation were similar and mainly included Proteobacteria, Actinobacteria, Acidobacteria, Bacteroidetes and Firmicutes. The relative abundance of soil bacteria and soil functional genes significantly differed across different types of vegetation. Among the four types of vegetation, soil bacteria under $P$. sylvestris exhibited the highest diversity, good potential for carbon accumulation and mitigation of nitrogen emissions. Therefore, $P$. sylvestris appears to be a suitable species in fixing mobile dunes and improving soil fertility more than the other three plant species in the Hulun Buir Sandy Land. Further studies investigating fungi in the Hulun Buir Sandy Land are necessary to reveal the detailed variation in soil microbes across revegetated plants, thus gaining a more complete understanding of the relationships among plant, soil and microbial communities in the desert ecosystems.

\section{Acknowledgements}

This study was supported by the National Key Research and Development Program of China (2016YFC0500905), the National Natural Science Foundation of China (31600584), and the Fundamental Research Funds for the Central Universities (2015ZCQSB-02). We would like to thank the staff of the Yanchi Research Station, School of Soil and Water Conservation, Beijing Forestry University, Beijing, China, with special thanks to Dr. QIN Shugao, Dr. LAI Zongrui, Dr. SUN Yanfei, Dr. LIU Zhen, Dr. BAI Yuxuan and Dr. SHE Weiwei for their help with the field and laboratory work.

\section{References}

Boeddinghaus R S, Marhan S, Berner D et al. 2019. Plant functional trait shifts explain concurrent changes in the structure and function of grassland soil microbial communities. Journal of Ecology, 107(5): 2197-2210. 
Cao H C, Chen R R, Wang L B, et al. 2016. Soil pH, total phosphorus, climate and distance are the major factors influencing microbial activity at a regional spatial scale. Scientific Reports, 6: 25815.

Castro S P, Cleland E E, Wagner R, et al. 2019. Soil microbial responses to drought and exotic plants shift carbon metabolism. The ISME Journal, 13: 1776-1787.

Che R X, Wang Y F, Li K X, et al. 2019. Degraded patch formation significantly changed microbial community composition in alpine meadow soils. Soil and Tillage Research, 195: 104426.

Chen D M, Mi J, Chu P F, et al. 2015. Patterns and drivers of soil microbial communities along a precipitation gradient on the Mongolian Plateau. Landscape Ecology, 30: 1669-1682.

Chen Y C, Sun J, Xie F T, et al. 2015. Litter chemical structure is more important than species richness in affecting soil carbon and nitrogen dynamics including gas emissions from an alpine soil. Biology and Fertility of Soils, 51: 791-800.

Chen Y L, Xu T L, Veresoglou S D, et al. 2017. Plant diversity represents the prevalent determinant of soil fungal community structure across temperate grasslands in northern China. Soil Biology and Biochemistry, 110: 12-21.

Cheng J M, Gang C C, Guo L, et al. 2017. Modification in Grassland Ecology under the Influence of Changing Climatic and Land Use Conditions. Plant Ecology: Traditional Approaches to Recent Trends, 43.

Deng L, Peng C H, Huang C B, et al. 2019. Drivers of soil microbial metabolic limitation changes along a vegetation restoration gradient on the Loess Plateau, China. Geoderma, 353: 188-200.

Du H S, Hasi E, Yang Y, et al. 2012. Landscape pattern change and driving force of blowout distribution in the Hulun Buir Sandy Grassland. Sciences in Cold and Arid Regions, 4: 431-438.

Edgar R C. 2010. Search and clustering orders of magnitude faster than BLAST. Bioinformatics, 26(19): 2460-2461.

Edgar R C, Haas B J, Clemente J C, et al. 2011. UCHIME improves sensitivity and speed of chimera detection. Bioinformatics, 27(16): 2194-2200.

Erisman J W, Sutton M A, Galloway J, et al. 2008. How a century of ammonia synthesis changed the world. Nature Geoscience, 1: 636 .

Evans S E, Wallenstein M D. 2014. Climate change alters ecological strategies of soil bacteria. Ecology Letters, 17(2): $155-164$.

Feng W, Zhang Y Q, Yan R, et al. 2019. Dominant soil bacteria and their ecological attributes across the deserts in northern China. European Journal of Soil Science, 1-12. doi: https://doi.org/10.1111/ejss.12866.

Ferran G P, Virginia L, Yevgeniy M, et al. 2013. Temperature drives the continental-scale distribution of key microbes in topsoil communities. Science, 340: 1574-1577.

Fierer N, Bradford M A, Jackson R B. 2007. Toward an ecological classification of soil bacteria. Ecology, 88(6): $1354-1364$.

Fierer N, Strickland M S, Liptzin D, et al. 2009. Global patterns in belowground communities. Ecology Letters, 12(11): 1238-1249.

Fierer N, Ladau J, Clemente J C, et al. 2013. Reconstructing the microbial diversity and function of pre-agricultural tallgrass prairie soils in the United States. Science, 342(6158): 621-624.

Fu B, Qi Y B, Chang Q R. 2015. Impacts of revegetation management modes on soil properties and vegetation ecological restoration in degraded sandy grassland in farming-pastoral ecotone. International Journal of Agricultural and Biological Engineering, 8(1): 26-34.

Goberna M, Pascual J A, García C, et al. 2007. Do plant clumps constitute microbial hotspots in semiarid Mediterranean patchy landscapes? Soil Biology and Biochemistry, 39(5): 1047-1054.

Goecks J, Nekrutenko A, Taylor J. 2010. Galaxy: a comprehensive approach for supporting accessible, reproducible, and transparent computational research in the life sciences. Genome Biology, 11(8): R86.

Griffiths R I, Thomson B C, James P, et al. 2011. The bacterial biogeography of British soils. Environmental Microbiology, 13(6): 1642-1654.

Gruber N, Galloway J N. 2008. An Earth-system perspective of the global nitrogen cycle. Nature, 451: 293-296.

Guo J, Wang T, Xue X, et al. 2010. Monitoring aeolian desertification process in Hulunbir grassland during 1975-2006, Northern China. Environmental Monitoring and Assessment, 166: 563-571.

Hacker N, Ebeling A, Gessler A, et al. 2015. Plant diversity shapes microbe-rhizosphere effects on P mobilisation from organic matter in soil. Ecology Letters, 18(12): 1356-1365.

Hayat R, Ali S, Amara U, et al. 2010. Soil beneficial bacteria and their role in plant growth promotion: a review. Annals of Microbiology, 60: 579-598.

Jangid K, Williams M A, Franzluebbers A J, et al. 2011. Land-use history has a stronger impact on soil microbial community composition than aboveground vegetation and soil properties. Soil Biology and Biochemistry, 43(10): $2184-2193$.

Jiang D M, Cao C Y, Zhang Y, et al. 2014. Plantations of native shrub species restore soil microbial diversity in the Horqin Sandy Land, northeastern China. Journal of Arid Land, 6: 445-453. 
Kim K Y, Jordan D, McDonald G. 1998. Enterobacter agglomerans, phosphate solubilizing bacteria, and microbial activity in soil: effect of carbon sources. Soil Biology and Biochemistry, 30(8-9): 995-1003.

Kozich J J, Westcott S L, Baxter N T, et al. 2013. Development of a dual-index sequencing strategy and curation pipeline for analyzing amplicon sequence data on the MiSeq Illumina sequencing platform. Applied and Environmental Microbiology, 79(17): 5112-5120.

Kuypers M M M, Marchant H K, Kartal B. 2018. The microbial nitrogen-cycling network. Nature Reviews Microbiology, 16: 263-276.

Langille M G, Zaneveld J, Caporaso J G, et al. 2013. Predictive functional profiling of microbial communities using 16S rRNA marker gene sequences. Nature Biotechnology, 31: 814-821.

Larsbrink J, Tuveng T R, Pope P B, et al. 2017. Proteomic insights into mannan degradation and protein secretion by the forest floor bacterium Chitinophaga pinensis. Journal of Proteomics, 156: 63-74.

Li J R, Okin G S, Alvarez L, et al. 2007. Quantitative effects of vegetation cover on wind erosion and soil nutrient loss in a desert grassland of southern New Mexico, USA. Biogeochemistry, 85: 317-332.

Li X R, Zhang P, Su Y G, et al. 2012. Carbon fixation by biological soil crusts following revegetation of sand dunes in arid desert regions of China: A four-year field study. Catena, 97: 119-126.

Li Y F, Li Z W, Wang Z Y, et al. 2017. Impacts of artificially planted vegetation on the ecological restoration of movable sand dunes in the Mugetan Desert, northeastern Qinghai-Tibet Plateau. International Journal of Sediment Research, 32: $277-287$.

Liao C R, Liu B C, Xu Y N, et al. 2019. Effect of topography and protecting barriers on revegetation of sandy land, Southern Tibetan Plateau. Scientific Reports, 9: 6501.

Liu Y M, Li X R, Xing Z S, et al. 2013. Responses of soil microbial biomass and community composition to biological soil crusts in the revegetated areas of the Tengger Desert. Applied Soil Ecology, 65: 52-59.

Madsen E L. 2011. Microorganisms and their roles in fundamental biogeochemical cycles. Currrent Opinion in Biotechnology, 22(3): 456-464.

Maestre F T, Quero J L, Gotelli N J, et al. 2012. Plant species richness and ecosystem multifunctionality in global drylands. Science, 335(6065): 214-218.

Magoč T, Salzberg S L. 2011. FLASH: fast length adjustment of short reads to improve genome assemblies. Bioinformatics, 27(21): 2957-2963.

Marcel G, Richard D, Nico M. 2008. The unseen majority: soil microbes as drivers of plant diversity and productivity in terrestrial ecosystems. Ecology Letters, 11(3): 296-310.

Miyasaka T, Okuro T, Miyamori E, et al. 2014. Effects of different restoration measures and sand dune topography on short-and long-term vegetation restoration in northeast China. Journal of Arid Environments, 111: 1-6.

Neilson J W, Quade J, Ortiz M, et al. 2012. Life at the hyperarid margin: novel bacterial diversity in arid soils of the Atacama Desert, Chile. Extremophiles, 16: 553-566.

Nelson M B, Martiny A C, Martiny J B. 2016. Global biogeography of microbial nitrogen-cycling traits in soil. Proceedings of the National Academy of Sciences, 113(29): 8033-8040.

Orlando J, Alfaro M, Bravo L, et al. 2010. Bacterial diversity and occurrence of ammonia-oxidizing bacteria in the Atacama Desert soil during a "desert bloom" event. Soil Biology and Biochemistry, 42(7): 1183-1188.

Özçelik M S, Gökbulak F, Şengönül K. 2019. Effect of vegetation patch size on selected chemical properties of soils under semiarid climate conditions. Forestist, 69: 117-123.

Pei S F, Fu H, Wan C G. 2008. Changes in soil properties and vegetation following exclosure and grazing in degraded Alxa desert steppe of Inner Mongolia, China. Agriculture, Ecosystems \& Environment, 124(1-2): 33-39.

Prober S M, Leff J W, Bates S T, et al. 2015. Plant diversity predicts beta but not alpha diversity of soil microbes across grasslands worldwide. Ecology Letters, 18(1): 85-95.

Schimel J P, Schaeffer S M. 2012. Microbial control over carbon cycling in soil. Frontiers in Microbiology, 3: 348.

Schneider T, Keiblinger K M, Schmid E, et al. 2012. Who is who in litter decomposition? Metaproteomics reveals major microbial players and their biogeochemical functions. The ISME Journal, 6: 1749-1762.

She W W, Bai Y X, Zhang Y Q, et al. 2018. Resource availability drives responses of soil microbial communities to short-term precipitation and nitrogen addition in a desert shrubland. Frontiers in Microbiology, 9: 186.

Shihan A, Hättenschwiler S, Milcu A, et al. 2017. Changes in soil microbial substrate utilization in response to altered litter diversity and precipitation in a Mediterranean shrubland. Biology and Fertility of Soils, 53: 171-185.

Sun L P, He LR, Wang G L, et al. 2019. Natural vegetation restoration of Liaodong oak forests rapidly increased the content and ratio of inert carbon in soil macroaggregates. Journal of Arid Land, 11(6): 928-938.

Sun Y F, Zhang Y Q, Feng W, et al. 2017. Effects of xeric shrubs on soil microbial communities in a desert in northern China. Plant and Soil, 414: 281-294. 
Tiwari K, Gupta R K. 2013. Diversity and isolation of rare actinomycetes: an overview. Critical Reviews in Microbiology, 39(3): 256-294.

Tu Q C, He Z L, Wu L Y, et al. 2017. Metagenomic reconstruction of nitrogen cycling pathways in a $\mathrm{CO}_{2}$-enriched grassland ecosystem. Soil Biology and Biochemistry, 106: 99-108.

Unc A, Maggs-Kölling G, Marais E, et al. 2019. Soil bacterial community associated with the dioecious Acanthosicyos horridus in the Namib Desert. Biology and Fertility of Soils, 55: 393-403.

Vered S T, Yosef S. 2011. Soil microbial diversity in the vicinity of a Negev Desert shrub-Reaumuria negevensis. Microbial Ecology, 61: 64-81.

Voriskova J, Baldrian P. 2013. Fungal community on decomposing leaf litter undergoes rapid successional changes. The ISME Journal, 7: 477-486.

Walkley A J, Black I A. 1934. An examination of the degtjareff method for determining soil organic matter, and a proposed modification of the chromic acid titration method. Soil Science, 37: 29-38.

Wang B Z, Zhang C X, Liu J L, et al. 2012. Microbial community changes along a land-use gradient of desert soil origin. Pedosphere, 22(5): 593-603.

Wang S K, Zhao X Y, Zhang T H, et al. 2013. Afforestation effects on soil microbial abundance, microbial biomass carbon and enzyme activity in dunes of Horqin Sandy Land, northeastern China. Sciences in Cold and Arid Regions, 5: 184-190.

Wang X B, van Nostrand J D, Deng Y, et al. 2015. Scale-dependent effects of climate and geographic distance on bacterial diversity patterns across northern China's grasslands. FEMS Microbiology Ecology, 91(12): fiv133. doi: 10.1093/femsec/fiv133.

Wang X B, Lu X T, Yao J, et al. 2017. Habitat-specific patterns and drivers of bacterial beta-diversity in China's drylands. The ISME Journal, 11: 1345-1358.

Wang X P, Quan G J, Pan Y X, et al. 2013. Comparison of hydraulic behaviour of unvegetated and vegetation stabilized sand dunes in arid desert ecosystems. Ecohydrology, 6(2): 264-274.

Xiao E Z, Krumins V, Xiao T F, et al. 2017. Depth-resolved microbial community analyses in two contrasting soil cores contaminated by antimony and arsenic. Environmental Pollution, 221: 244-255.

Yadav R S, Yadav B L, Chhipa B R, et al. 2011. Soil biological properties under different tree based traditional agroforestry systems in a semi-arid region of Rajasthan, India. Agroforestry Systems, 81: 195-202.

Yang H T, Li X R, Wang Z R, et al. 2014. Carbon sequestration capacity of shifting sand dune after establishing new vegetation in the Tengger Desert, northern China. Science of the Total Environment, 478: 1-11.

Yu L Z, Luo X S, Liu M, et al. 2015. Diversity of ionizing radiation-resistant bacteria obtained from the Taklimakan Desert. Journal of Basic Microbiology, 55(1): 135-140.

Yuan J Y, Ouyang Z Y, Zheng H, et al. 2012. Effects of different grassland restoration approaches on soil properties in the southeastern Horqin sandy land, northern China. Applied Soil Ecology, 61: 34-39. (in Chinese)

Zeng Q C, An S S, Liu Y. 2017. Soil bacterial community response to vegetation succession after fencing in the grassland of China. Science of the Total Environment, 609: 2-10.

Zhang H F, Song X L, Wang C L, et al. 2013a. The effects of different vegetation restoration patterns on soil bacterial diversity for sandy land in Hulunbeier. Acta Ecologica Sinica, 33(4): 211-216. (in Chinese)

Zhang H F, Li G, Song X L, et al. 2013b. Changes in soil microbial functional diversity under different vegetation restoration patterns for Hulunbeier Sandy Land. Acta Ecologica Sinica, 33(1): 38-44. (in Chinese)

Zhang W, Zhang G S, Liu G X, et al. 2012. Bacterial diversity and distribution in the southeast edge of the Tengger Desert and their correlation with soil enzyme activities. Journal of Environmental Sciences, 24: 2004-2011.

Zhang W, Xu Y D, Gao D X, et al. 2019. Ecoenzymatic stoichiometry and nutrient dynamics along a revegetation chronosequence in the soils of abandoned land and Robinia pseudoacacia plantation on the Loess Plateau, China. Soil Biology and Biochemistry, 134: 1-14.

Zhang X M, Zhang G M, Chen Q S, et al. 2013. Soil bacterial communities respond to climate changes in a temperate steppe. PLoS ONE, 8: e78616.

Zhang Y, Cao C Y, Cui Z B, et al. 2019. Soil bacterial community restoration along a chronosequence of sand-fixing plantations on moving sand dunes in the Horqin sandy land in northeast China. Journal of Arid Environments, 165: 81-87.

Zhao L N, Liu Y B, Wang Z R, et al. 2019. Bacteria and fungi differentially contribute to carbon and nitrogen cycles during biological soil crust succession in arid ecosystems. Plant and Soil, 447: 379-392.

Zhou Y, Qin Y Q, Liu X D, et al. 2019. Soil bacterial function associated with stylo (legume) and bahiagrass (grass) is affected more strongly by soil chemical property than by bacterial community composition. Frontiers in Microbiology, 10: 798. 


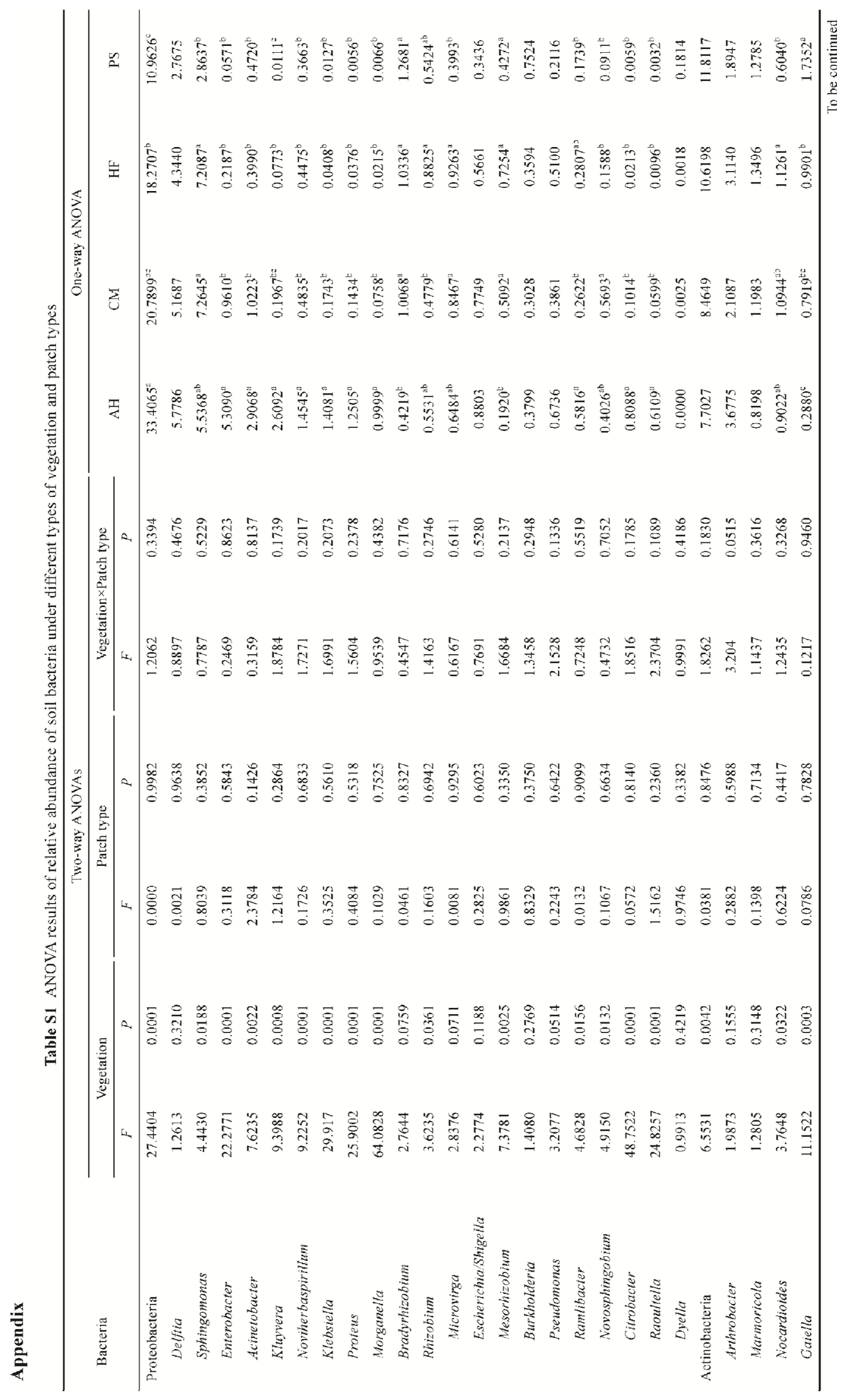




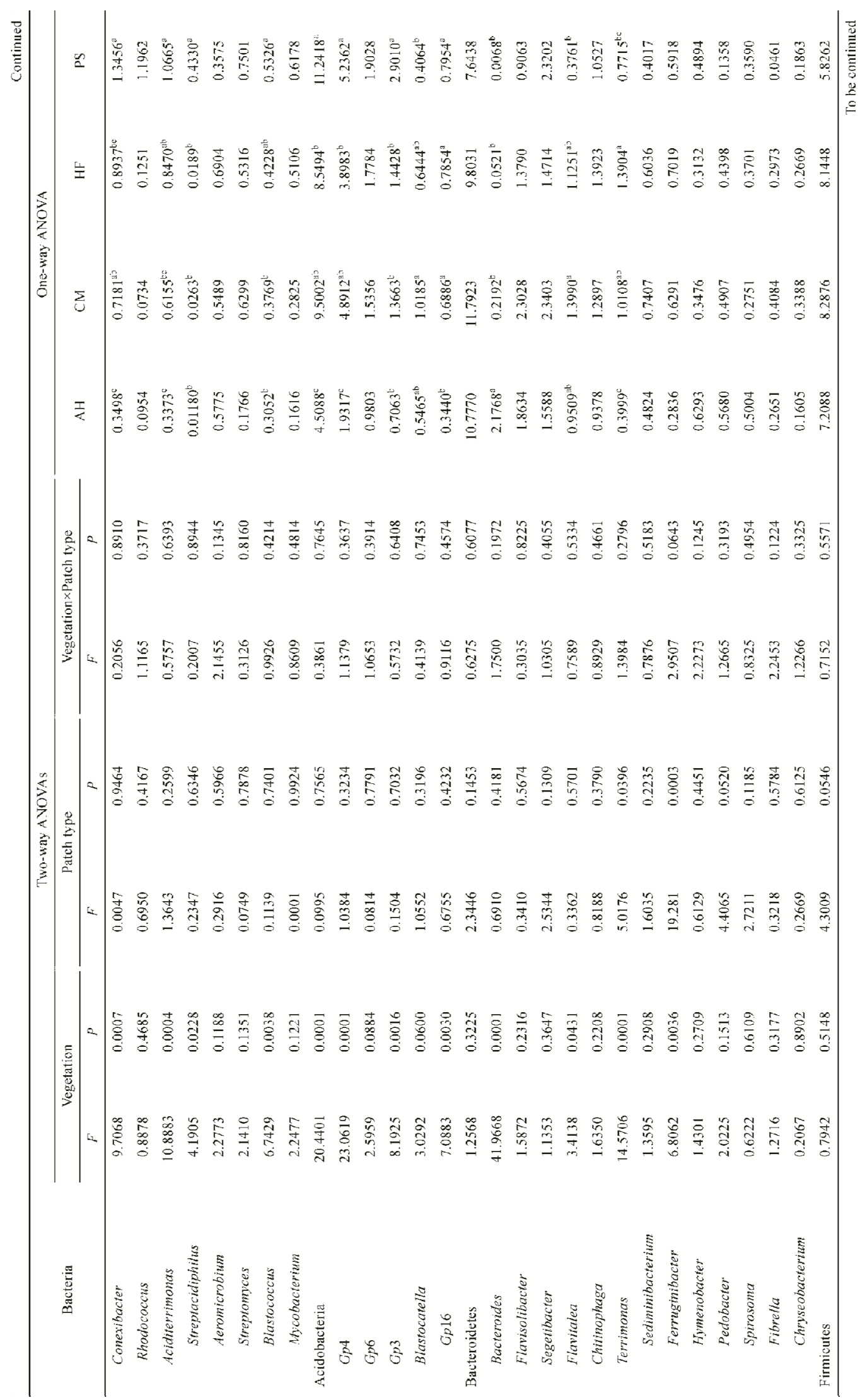




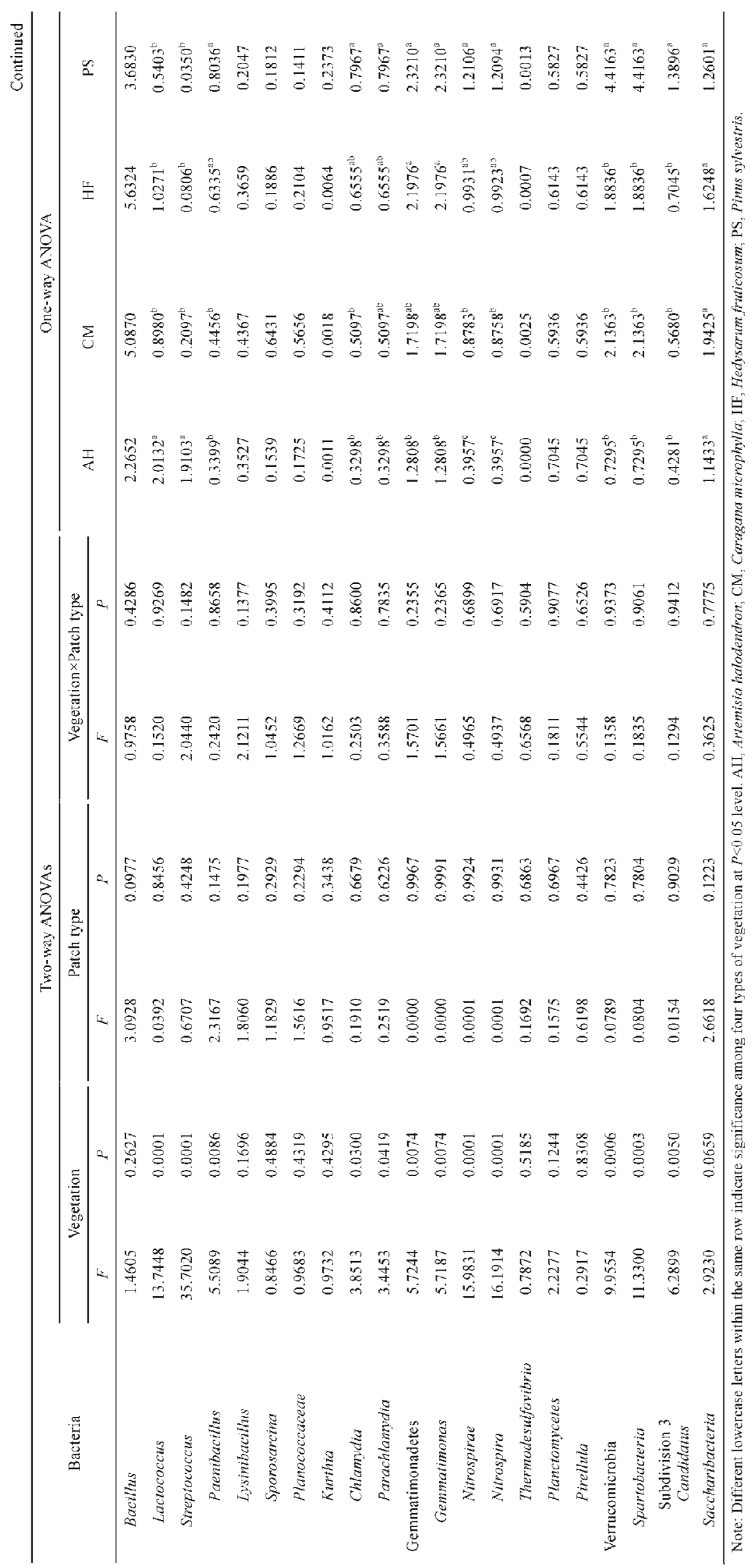




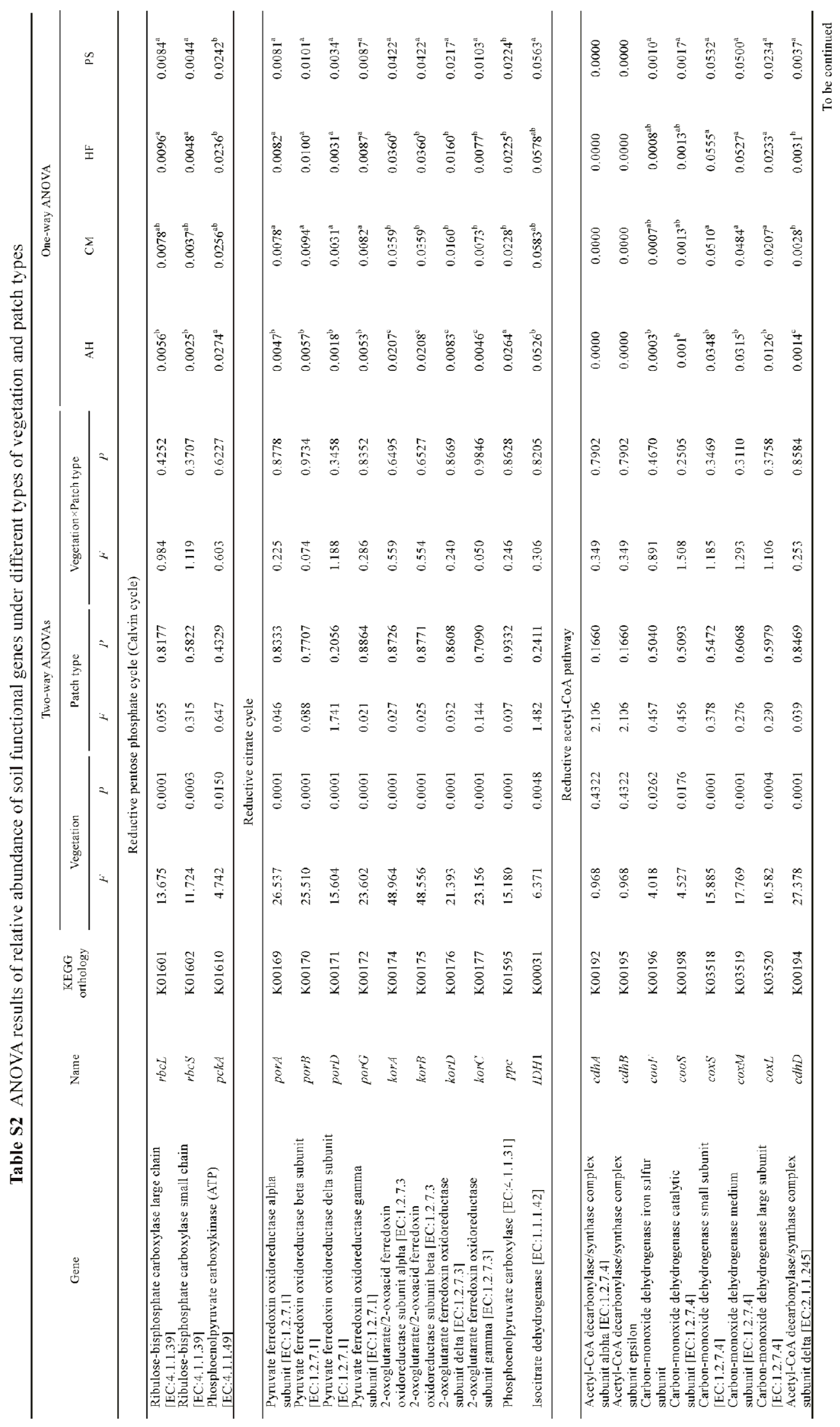




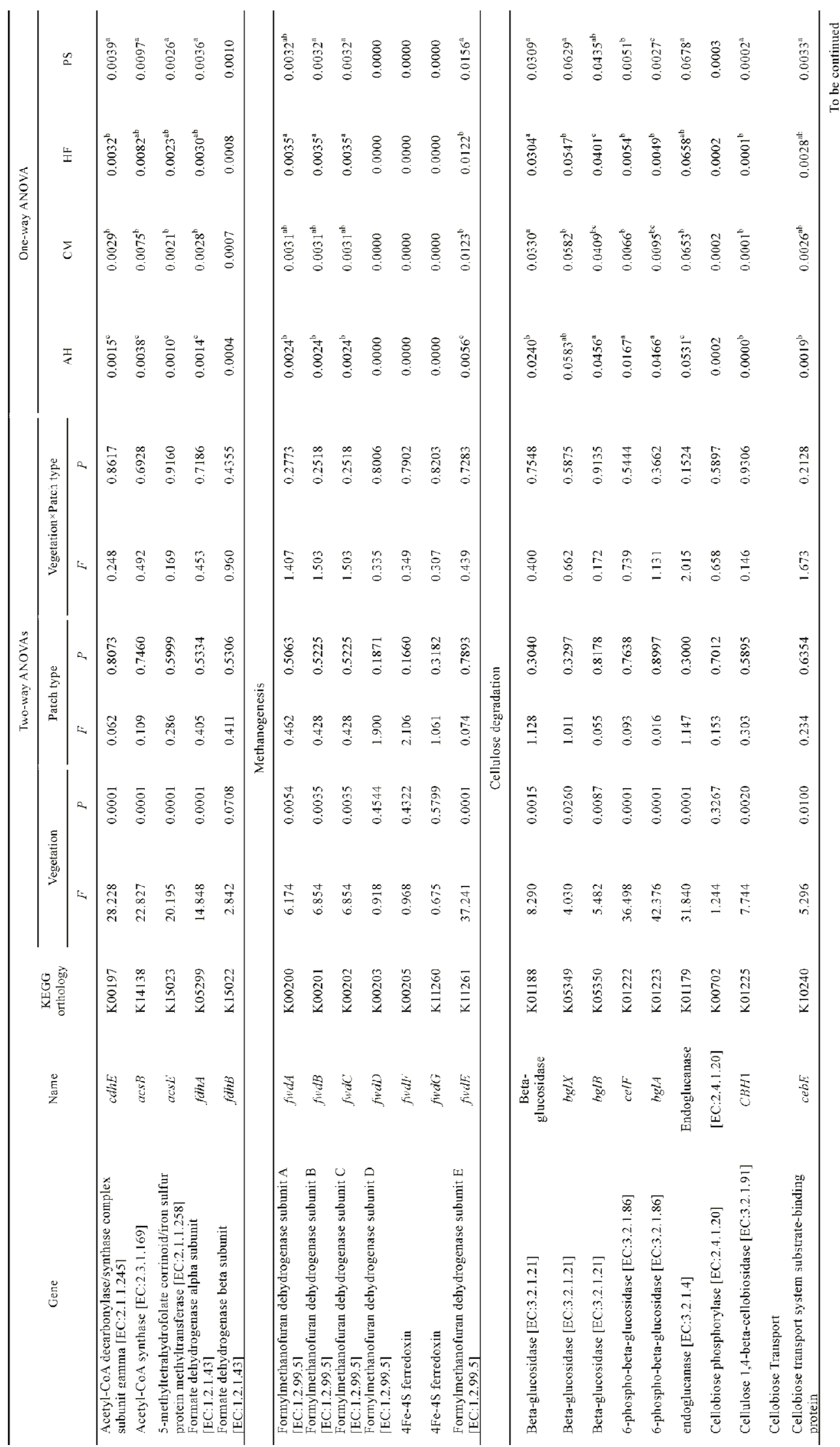




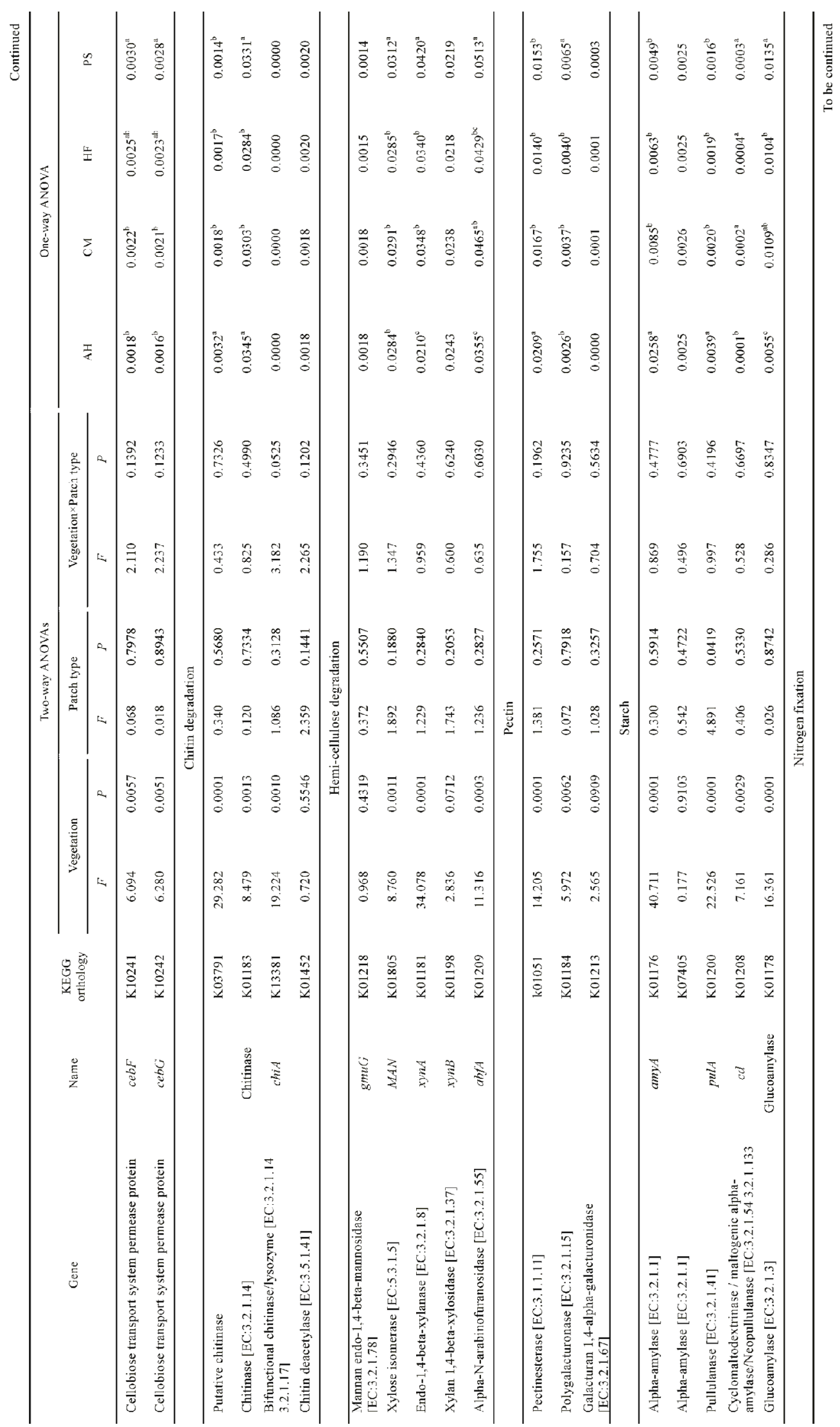




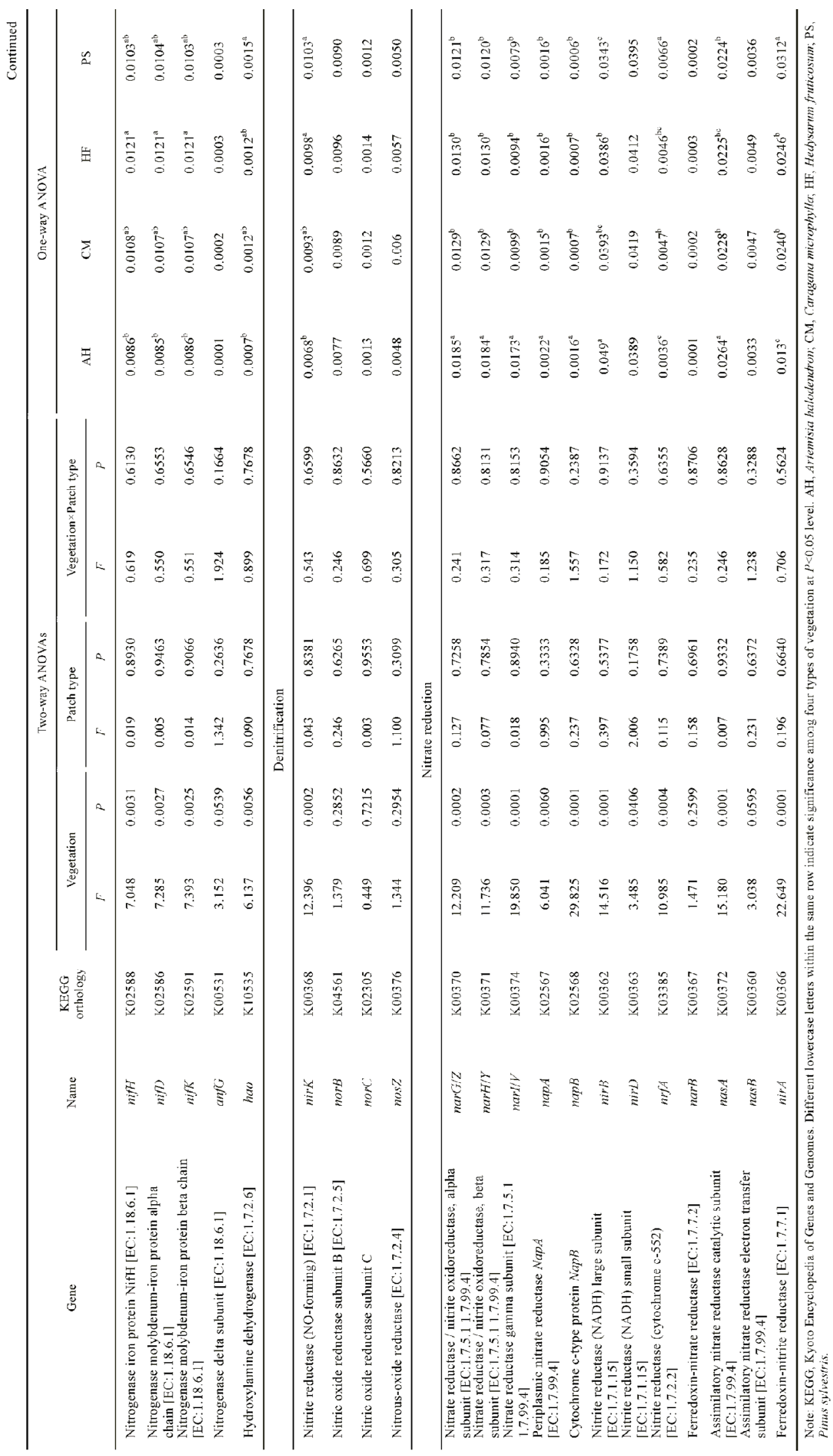

